\title{
Influence of Ripening in Mother Solution on Characteristics of Magnesium-Substituted Calcium Phosphate Powders
}

\author{
M. A. Goldberg ${ }^{a}$, V. V. Smirnov ${ }^{a}$, O. S. Antonova ${ }^{a}$, L. I. Shvorneva ${ }^{a}$, A. A. Konovalov ${ }^{a}$, \\ E. A. Kudryavtsev ${ }^{b}$, S. V. Smirnov ${ }^{a}$, and S. M. Barinov ${ }^{a}$ \\ ${ }^{a}$ Baikov Institute of Metallurgy and Materials Science, Russian Academy of Sciences, Moscow, Russia \\ ${ }^{b}$ Belgorod National Research University, Belgorod, Russia \\ e-mail: naiv.syper@gmail.com \\ Received May 12, 2016
}

\begin{abstract}
Effect of ripening in the mother liquor on the degree of crystallinity and dispersity of mixed powders of calcium and magnesium phosphates is studied as a function of magnesium content with the elemental composition such that $(\mathrm{Ca}+\mathrm{Mg}) / \mathrm{P}=2$. Ripening is found to have a positive effect on crystallinity of the apatite phase of powders. Nanocrystals with lowered tendency to aggregation are formed during the ripening period, which affords the powders with specific surface area as high as $80 \mathrm{~m}^{2} / \mathrm{g}$. The morphology of the constituent particles depends on the magnesium content. Crystallization processes are essentially completed by the 21 st day of ripening.
\end{abstract}

Keywords: calcium phosphates, magnesium phosphates, ripening in mother liquor, powder synthesis

DOI: $10.1134 /$ S2075113317010130

\section{INTRODUCTION}

Inclusion of magnesium in composites based on calcium phosphate is of great interest owing to the possibility of enhancing the rate of bioresorption of bone matrices [1]. Moreover, magnesium is known to stimulate osteoblast proliferation, thus encouraging osteogenesis [2]. Adding magnesium to powders based on hydroxyapatite (HA) increases their degree of dispersion owing to a known destabilizing effect of magnesium on the HA structure [3]. Also, preparation of powders with a high degree of dispersion is an important condition in ceramics technology, as this affects the properties of the finished products. Hydrothermal synthesis was employed to prepare magnesium-substituted calcium phosphate powders that were characterized by a specific surface area up to $A_{\mathrm{sp}}=62.3 \mathrm{~m}^{2} / \mathrm{g}$ and a degree of magnesium substitution up to $14 \mathrm{wt} \%$ [4]. For calcium phosphate powders with a higher degree of magnesium substitution, $A_{\mathrm{sp}}$ was less than $36 \mathrm{~m}^{2} / \mathrm{g}$ [5].

One of the approaches to increase the dispersion grade of calcium phosphate powders is based on ripening in the mother liquor; this was applied to an HA-calcium carbonate system previously [6]. With this approach, the degree of dispersion of a powder increases as a result of an enhancement in the solid phase crystallinity and formation of nanocrystals from the amorphous particles. Previous studies established that, if the amount of magnesium was such that $(\mathrm{Ca}+$ $\mathrm{Mg}) / \mathrm{P}=2$, the crystal lattice was characterized by a higher degree of lattice distortion; that is, the synthesized powders had an elevated content of the amorphous phase [5]. With this in mind, it seems reasonable to expect that ripening in the mother liquor, which improves the crystallinity of the precipitate, will readily produce sinterable nanocrystallites. This issue is addressed in the present work.

\section{EXPERIMENTAL}

The powders of mixed calcium and magnesium phosphates with the elemental composition such that $(\mathrm{Ca}+\mathrm{Mg}) / \mathrm{P}=2$, for which the influence of ripening on the crystallinity of powders was studied, were obtained by precipitation from aqueous solutions; namely, solutions of calcium and magnesium nitrates were mixed with a diammonium hydrogen phosphate solution in a ratio that meets that the elemental composition given above. The precipitates were then allowed to age for $0,3,7,14$, or 21 days at $37^{\circ} \mathrm{C}$. The degree of magnesium substitution was $0,5,10,20$, or $40 \mathrm{wt} \%$. An ammonia solution was added to the reaction systems to maintain their $\mathrm{pH}$ in the range of 9-10. After ripening was complete, the precipitates upon removal of the main part of water by evaporation were dried at $50^{\circ} \mathrm{C}$ and then subjected to thermal treatment at $300^{\circ} \mathrm{C}$ in air.

The powdered materials were subjected to X-ray powder diffraction analysis (XRD) on a Shimadzu XRD-6000 (Japan) diffractometer using $\mathrm{Cu} K_{\alpha}$ radia- 


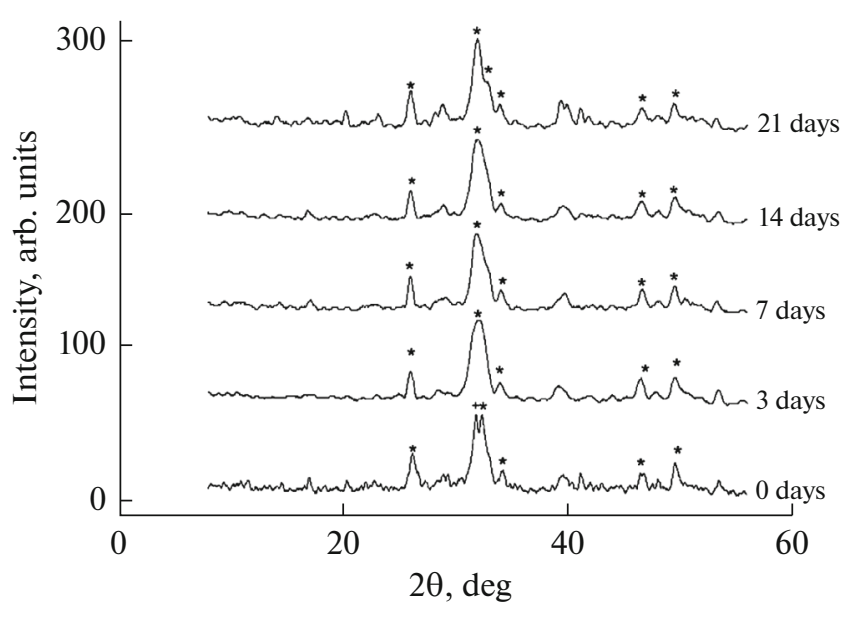

Fig. 1. XRD patterns of the powders with $0 \mathrm{wt} \%$ magnesium substitution and ripening time ranging from 0 to 21 days. Peaks due to $(*)$ apatite and $(+) \mathrm{Ca}(\mathrm{OH})_{2}$ phases.

tion. The phase content was analyzed with PCPDFWIN software in accord with the JCPDS database using an automated system for data recording and processing. Specific surface area of the powders $A_{\text {sp }}$ was derived from the BET analysis of the low-temperature nitrogen adsorption measurements performed on a Tristar Micromeretics surface area and porosity analyzer. For microscopic characterization of the powders (the size and shape of the constituent particles), scanning electron microscopy was performed on a VEGA II (TESCAN) microscope using the mode of detection of secondary electrons and an accelerating voltage of $15 \mathrm{kV}$.

\section{RESULTS AND DISCUSSION}

The XRD data of the sample with 0 wt $\%$ magnesium substitution, that is, without $\mathrm{Mg}$, and zero ripening reveal the formation of a halo in the apatite phase region and a peak characteristic of the $\mathrm{Ca}(\mathrm{OH})_{2}$ phase (Fig. 1). The XRD patterns show that the $\mathrm{Ca}(\mathrm{OH})_{2}$ phase disappears and only the apatite phase remains for the samples with increasing ripening period. Also, progressive diminution of the width of peaks and their higher resolution suggest an improvement in the crystallinity of samples as the ripening time increases.

For the samples with 5 wt $\%$ magnesium substitution, only the apatite phase is detected immediately after the synthesis; the degree of crystallinity of the apatite phase is greatly enhanced in the "older" samples, as can be concluded from the higher intensity of the main peaks (Fig. 2). As for the samples with 0\% magnesium substitution, well-resolved peaks in the regions specific to the apatite phase can be observed for the sample with 21 days of ripening.

The apatite phase in the samples with $10 \mathrm{wt} \%$ magnesium substitution possesses a low degree of crystallinity, which does not noticeably improve with ripening time. The fresh samples ( 0 days of ripening) with

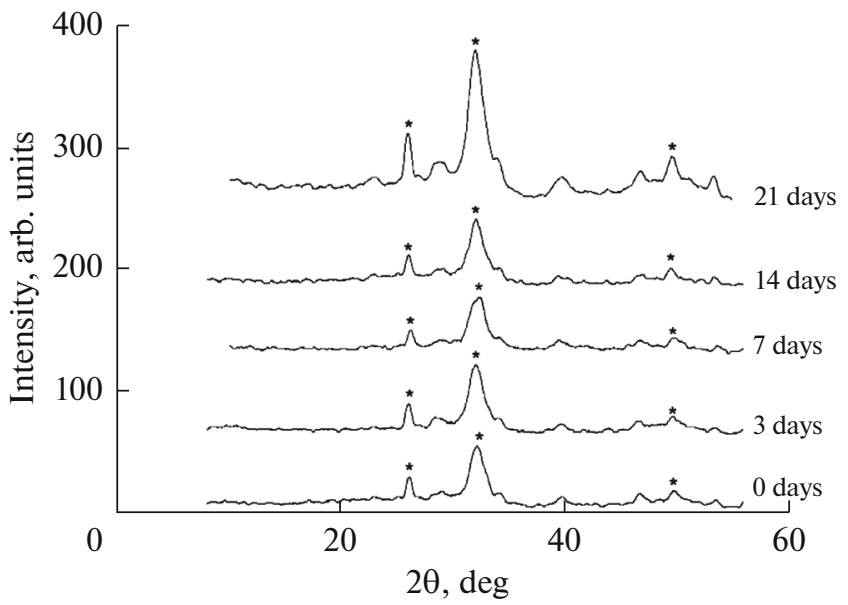

Fig. 2. XRD patterns of the powders with $5 \mathrm{wt} \%$ magnesium substitution and ripening time ranging from 0 to 21 days: (*) apatite phase.

20 and $40 \mathrm{wt} \%$ magnesium substitution are found to be X-ray amorphous (Fig. 3). The apatite phase is formed in the samples with nonzero ripening time; its crystallinity improves as the ripening time increases. The XRD patterns of the specimen with 3 days of ripening show a halo in the apatite phase region, and for the samples with 7 days of ripening, significantly broader peaks are observed.

It can be concluded that ripening in mother liquor contributes to the stabilization of the apatite phase structure. Incorporation of magnesium leads to the destabilization of the structure of the materials, as the fresh samples with level of magnesium substitution of 20 and $40 \mathrm{wt} \%$ were found to be X-ray amorphous. In the course of the ripening process, the XRD patterns of the $\mathrm{Mg}$-containing materials reveal the formation of a halo for the less aged samples and the emergence of

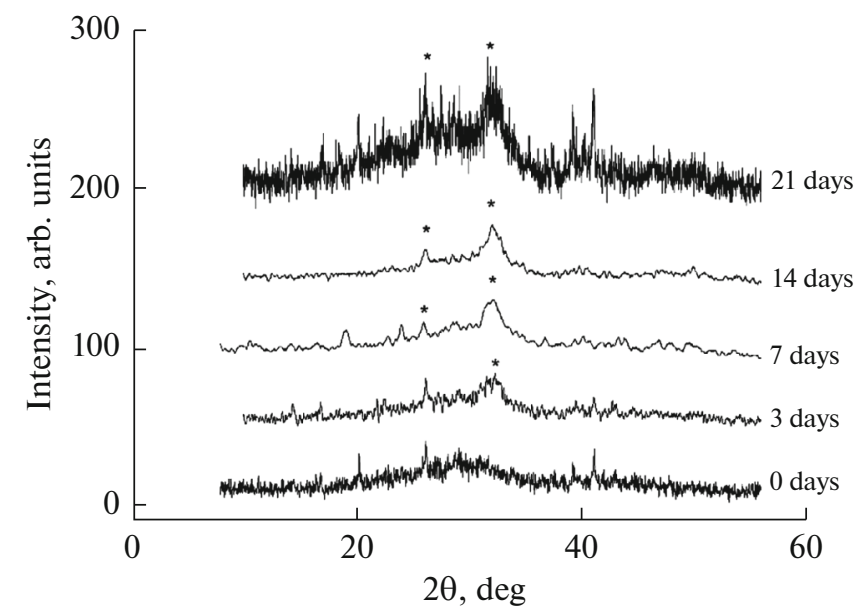

Fig. 3. XRD patterns of the powders with $40 \mathrm{wt} \%$ magnesium substitution and ripening time ranging from 0 to 21 days: (*) apatite phase. 

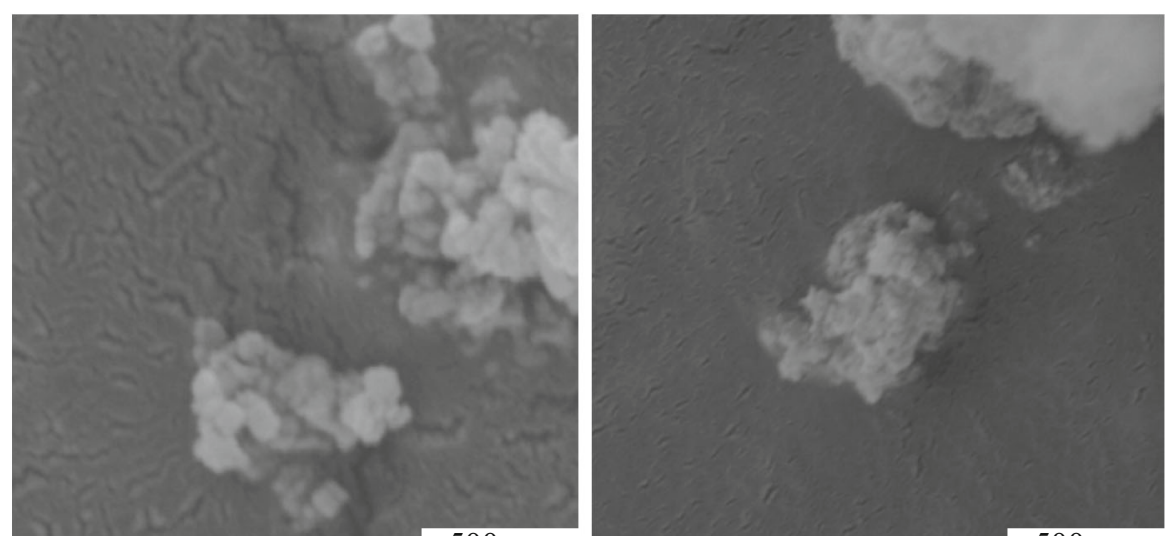

(a)

$500 \mathrm{~nm}$

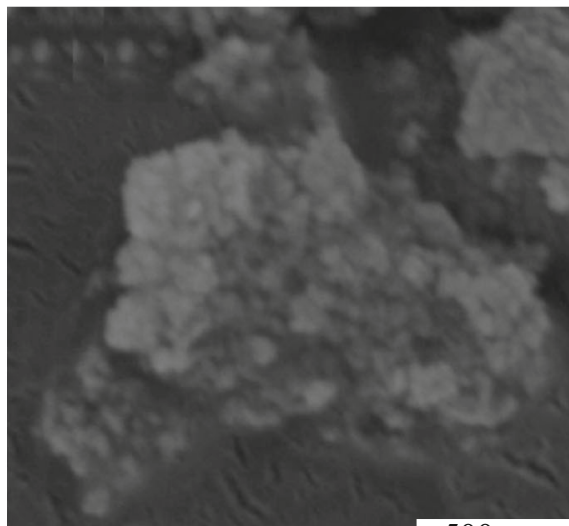

(b)

$500 \mathrm{~nm}$

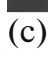

$500 \mathrm{~nm}$
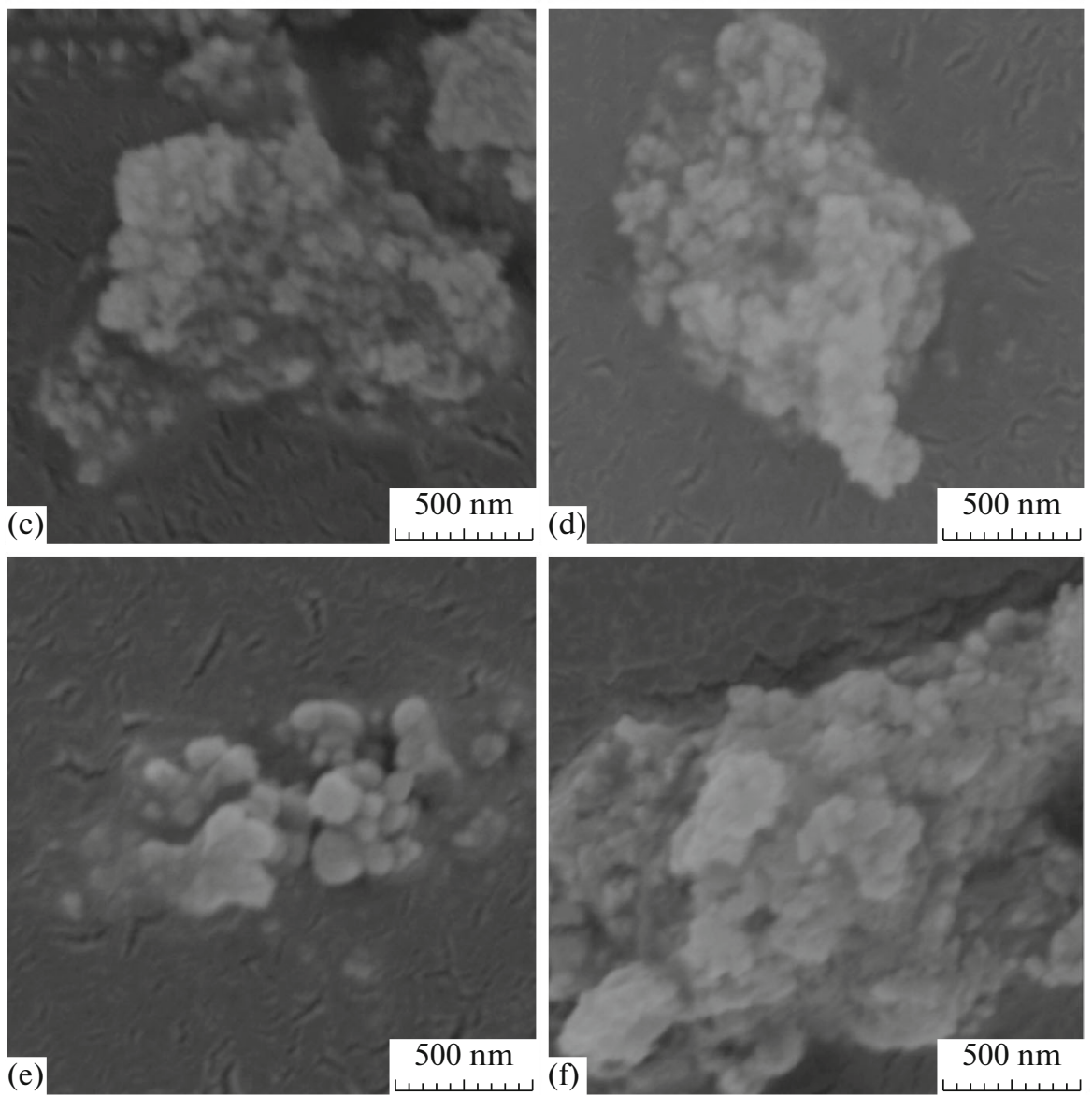

Fig. 4. SEM images of the powders with different degrees of magnesium substitution and ripening time: (a) 5 wt $\%$ and 0 days; (b) $5 \mathrm{wt} \%$ and 21 days; (c) $20 \mathrm{wt} \%$ and 0 days; (d) $20 \mathrm{wt} \%$ and 21 days; (e) $40 \mathrm{wt} \%$ and 0 days; (f) $40 \mathrm{wt} \%$ and 21 days.

peaks characteristic of the apatite phase for the more aged samples.

The BET analysis showed that $A_{\text {sp }}$ greatly increases with (ripening) time. This is related to the formation of superfine crystals from the (slowly crystallizing) amorphous phase, as was corroborated by the XRD data showing an enhancement in the crystallinity of the powders under study. The powders with zero ripening time and high amorphous phase content became denser and lost water and some other reaction products following the thermal treatment; relatively large and dense conglomerates ensued, which lessened $A_{\text {sp }}$. For older samples, the formation of conglomerates was not as pronounced because the formed nanocrystals were characterized by a reduced activity in comparison with the amorphous phase of the material, which results in an increase in $A_{\mathrm{sp}}$ (see table). The highest value $\left(A_{\mathrm{sp}}=79.62 \pm 0.50 \mathrm{~m}^{2} / \mathrm{g}\right)$ was obtained 
Effect of ripening time on specific surface area of the powders $A_{\mathrm{sp}}$

\begin{tabular}{c|c|c|c|c|c}
\hline \multirow{2}{*}{$\begin{array}{c}\text { Degree } \\
\text { of magnesium } \\
\text { substitution, } \\
\text { wt } \%\end{array}$} & $\begin{array}{c}\text { 0 days } \\
\text { of ripening }\end{array}$ & $\begin{array}{c}3 \text { days } \\
\text { of ripening }\end{array}$ & $\begin{array}{c}7 \text { days } \\
\text { of ripening }\end{array}$ & $\begin{array}{c}14 \text { days } \\
\text { of ripening }\end{array}$ & $\begin{array}{c}21 \text { days } \\
\text { of ripening }\end{array}$ \\
\cline { 2 - 6 } & $20.9 \pm 0.1$ & $21.59 \pm 0.23$ & $67.57 \pm 0.71$ & $17.33 \pm 0.25$ & $17.21 \pm 0.46$ \\
5 & $39.2 \pm 1.8$ & $70.99 \pm 0.58$ & $55.14 \pm 0.49$ & $58.90 \pm 0.68$ & $57.51 \pm 0.26$ \\
10 & $26.6 \pm 1.0$ & $79.62 \pm 0.50$ & $26.11 \pm 0.29$ & $24.76 \pm 0.19$ & $14.44 \pm 0.52$ \\
20 & $36.5 \pm 1.1$ & $34.9 \pm 0.40$ & $38.27 \pm 0.60$ & $29.84 \pm 0.60$ & $41.36 \pm 1.00$ \\
40 & $22.8 \pm 0.4$ & $17.63 \pm 0.40$ & $14.44 \pm 0.52$ & $38.60 \pm 0.61$ & $24.60 \pm 0.50$ \\
\hline
\end{tabular}

for the specimens that had the degree of magnesium substitution of $10 \mathrm{wt} \%$ and with the ripening time of at least three days. It was established that a considerable increase in $A_{\text {sp }}$ was observed on the third and the seventh days of ripening, and on the 21st day, $A_{\mathrm{sp}}$ stopped increasing, which points to the completion of the processes associated with the apatite phase growth and the beginning of the crystal growth.

The SEM images of the powders that were not subjected to ripening show large agglomerates of irregular shapes composed of round-shaped particles (Figs. 4a, 4c, $4 \mathrm{e})$; the size of particles of the materials changes with increasing magnesium content. $\mathrm{Mg}$-free materials also contained round-shaped particles having size from 50 to $100 \mathrm{~nm}$. For the powders with $5 \mathrm{wt} \%$ magnesium substitution, the particle size was less than $100 \mathrm{~nm}$; as the magnesium content was increased to $20 \mathrm{wt} \%$, the particle size decreased and did not exceed $50 \mathrm{~nm}$; and for powders with $40 \mathrm{wt} \%$ magnesium substitution, some particles measured up to $100 \mathrm{~nm}$.

The microstructure of the powders subjected to 21 days of ripening consisted of agglomerates as large as $1 \mu \mathrm{m}$ that were made of particles of irregular (asymmetric) shape, as shown in Figs. 4b, 4d, and 4f. A slight decrease in the particle size was also noted. The powders with magnesium substitution of up to $20 \mathrm{wt} \%$ consisted of particles whose size was $50 \mathrm{~nm}$ or less, while for the powders characterized by $40 \mathrm{wt} \%$ magnesium substitution, the particles were within the range of $50-70 \mathrm{~nm}$.

\section{CONCLUSIONS}

It has been established that ripening in mother liquor is conducive to stabilization of the crystalline structure of the apatite phase and formation of nanocrystals with only a minor degree of aggregation, which renders materials with specific surface area as high as $80 \mathrm{~m}^{2} / \mathrm{g}$ (to be precise, for the powder with $10 \mathrm{wt} \%$ magnesium substitution, $A_{\mathrm{sp}}=79.62 \pm 0.50 \mathrm{~m}^{2} / \mathrm{g}$ ). We observed a considerable increase in $A_{\text {sp }}$ on the third and the seventh day of ripening, and by the 21 st day, $A_{\text {sp }}$ reached a stable level, which suggests that the processes associ- ated with the apatite phase growth reach completion, and the crystal growth commences. At the same time, the constituent particles change their shape and decrease in size: the powders with magnesium substitution up to $20 \mathrm{wt} \%$ were made of particles $50 \mathrm{~nm}$ or less in size; while particles $50-70 \mathrm{~nm}$ in size were found in powders with $40 \mathrm{wt} \%$ magnesium substitution.

\section{ACKNOWLEDGMENTS}

This work was supported by the Russian Science Foundation, project no. 16-13-00123.

\section{REFERENCES}

1. Webster, T.J., Ergun, C., Doremus, R.H., and Bizios, R., Hydroxylapatite with substituted magnesium, zinc, cadmium, and yttrium. II. Mechanisms of osteoblast adhesion, J. Biomed. Mater. Res., 2002, vol. 59, no. 2, pp. 312-317.

2. Liu, C.C., Yeh, J.K., and Aloia, J.F., Magnesium directly stimulates osteoblast proliferation, J. Bone Miner. Res., 1988, vol. 3, suppl. 1, p. S104.

3. Barinov, S.M., Calcium phosphate-based ceramic and composite materials for medicine, Russ. Chem. Rev., 2010, vol. 79, no. 1, pp. 13-29.

4. Chaudhry, A.A., Goodall, J., Vickers, M., Cockcroft, J.K., Rehman, I., Knowles, J.C., and Darr, J.A., Synthesis and characterisation of magnesium substituted calcium phosphate bioceramic nanoparticles made via continuous hydrothermal flow synthesis, J. Mater. Chem., 2008, vol. 18, no. 48, pp. 5900-5908.

5. Goldberg, M.A., Smirnov, V.V., Kasimova, M.R., Shvorneva, L.I., Kutsev, S.V., Antonova, O.S., and Barinov, S.M., Ceramics in the system calcium phosphates-magnesium phosphates with $(\mathrm{Ca}+\mathrm{Mg}) / \mathrm{P} \approx 2$, Dokl. Chem., 2015, vol. 461, no. 1, pp. 81-85.

6. Gol'dberg, M.A., Smirnov, V.V., Ievlev, V.M., Barinov, S.M., Kutsev, S.V., Shibaeva, T.V., and Shvorneva, L.I., Influence of ripening time on the properties of hydroxyapatite-calcium carbonate powders, Inorg. Mater., 2012, vol. 48, no. 2, pp. 181-186.

Translated by A. Cuharuc 